\title{
Single-anastomosis duodeno-ileal - new revision procedure in a patient with insufficient weight loss after sleeve gastrectomy
}

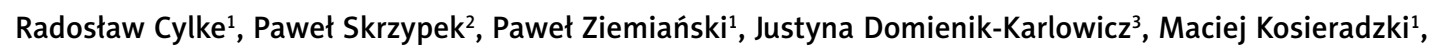 \\ Wojciech Lisik ${ }^{1}$ \\ ${ }^{1}$ Department of General and Transplantation Surgery, Medical University of Warsaw, Warsaw, Poland \\ ${ }^{2}$ Student Research Group, Department of General and Transplantation Surgery, Medical University of Warsaw, Warsaw, Poland \\ ${ }^{3}$ Department of Internal Medicine and Cardiology, Medical University of Warsaw, Warsaw, Poland
}

Videosurgery Miniinv 2018; 13 (3): 407-411 DOI: https://doi.org/10.5114/wiitm.2018.76686

\begin{abstract}
Laparoscopic sleeve gastrectomy (LSG) is one of the most popular and effective bariatric surgical procedures worldwide. The effect of LSG is mostly dependent on the restrictive mechanism, which makes it more vulnerable to failure. Failing of bariatric procedure is not uncommon and occurs in $6 \%$ to $23 \%$. In case of weight loss failure, there are no hard recommendations on the choice of the redo procedure. One of the most novel options, introduced in 2007, relatively simple to perform following $L S G$ is single-anastomosis duodenoileal bypass. Herein we describe surgical technique and history of a patient with inadequate weight loss after laparoscopic sleeve gastrectomy, who underwent single-anastomosis duodenoileal bypass.
\end{abstract}

Key words: laparoscopic sleeve gastrectomy, bariatric surgery, single-anastomosis duodenoileal.

\section{Introduction}

Laparoscopic sleeve gastrectomy (LSG) is one of the most popular and effective bariatric surgical procedures worldwide. The effect of LSG is mostly dependent on the restrictive mechanism, which makes it more vulnerable to failure [1]. Failure of bariatric procedures is not uncommon and occurs in $6 \%$ to $23 \%$ of cases [2]. Inadequate weight loss can be defined as an initial loss of less than $50 \%$ of excess weight loss (EWL), or relapse of body mass index $(\mathrm{BMI})>35 \mathrm{~kg} / \mathrm{m}^{2}$ [3]. The most likely factor behind this is the patient's noncompliance, especially regarding dietary restrictions [4]. In the case of weight loss failure, there are no hard recommendations on the choice of the redo procedure [2, 5-10]. One of the most novel options, relatively simple to perform following LSG, is single-anasto- mosis duodenoileal bypass with sleeve gastrectomy (SADI-S) [11, 12].

SADI-S was introduced in 2007 as a shorter, safer and equally effective modified version of biliopancreatic diversion with duodenal switch [13]. As the name suggests, SADI-S combines two bariatric procedures LSG and duodeno-ileal bypass. This makes it a perfect option for patients after ineffective sleeve gastrectomy.

Herein, we report a case of a patient with inadequate weight loss after laparoscopic sleeve gastrectomy who underwent the malabsorptive part of SADI-S, with our insights into this procedure.

\section{Technical report}

\section{Failure of first bariatric surgery}

A 46-year-old obese woman presented at the Bariatric Outpatient Clinic. On her first visit she

\section{Address for correspondence}

Justyna Domienik-Karlowicz MD, PhD, Department of Internal Medicine and Cardiology, Medical University of Warsaw,

59 Nowogrodzka St, 02-005 Warsaw, Poland, phone: +48 2250211 44, e-mail: jdomienik@tlen.pl 


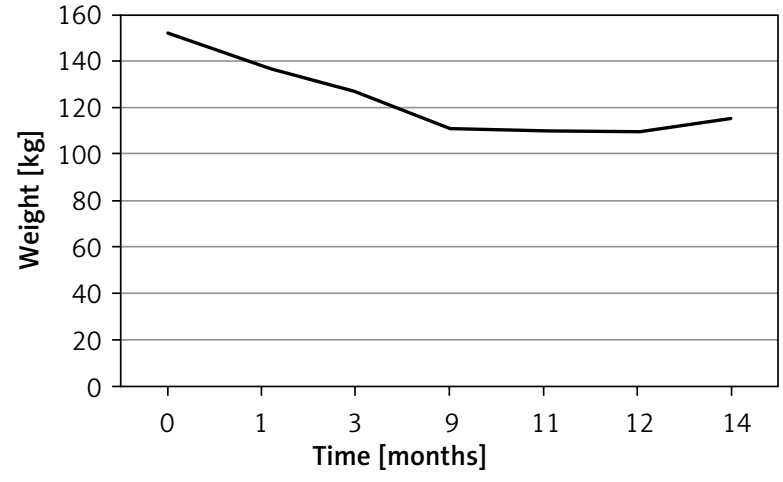

Figure 1. Weight loss after LSG

qualified as a super-obese patient [14] with BMI of $53.6 \mathrm{~kg} / \mathrm{m}^{2}$, weighing $151.9 \mathrm{~kg}$. She suffered from hypertension, depression and treated hypothyroidism. After standard laboratory tests and consultations she was qualified for laparoscopic sleeve gastrectomy. The procedure was performed without any complications. The volume of the resected stomach was $900 \mathrm{ml}$, measured by filling the specimen with $\mathrm{CO}_{2}$ under pressure of $20 \mathrm{~mm} \mathrm{Hg}$. During 9 months after surgery, the patient's weight loss was satisfactory. Later on, despite the patient's declaration of full compliance and numerous attempts of changing exercise plans, the progress stopped (Figures 1, 2). In the meantime she underwent laparoscopic cholecystectomy for symptomatic gallstones.

Fourteen months after the initial operation, the patient's BMI remained over $40 \mathrm{~kg} / \mathrm{m}^{2}$ and excess weight loss was $41.1 \%$, which fulfilled the criteria of inadequate weight loss [3]. Considering all these facts and the patient's general dissatisfaction with the results, the second bariatric procedure was scheduled. As the restrictive part of the operation

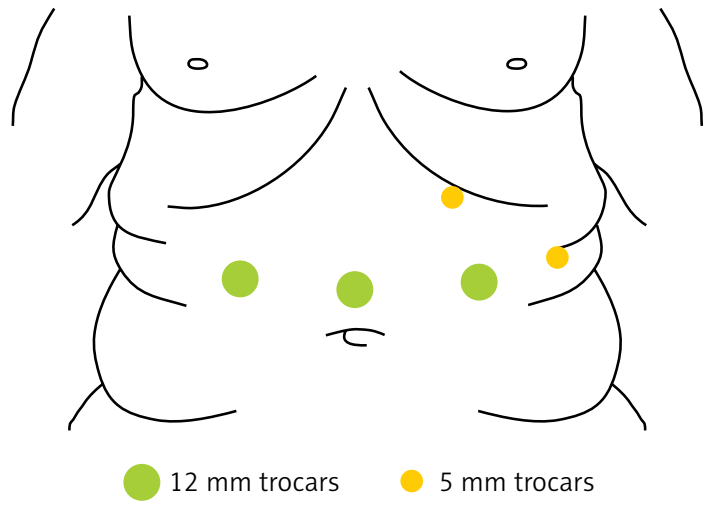

Figure 3. Trocar placement

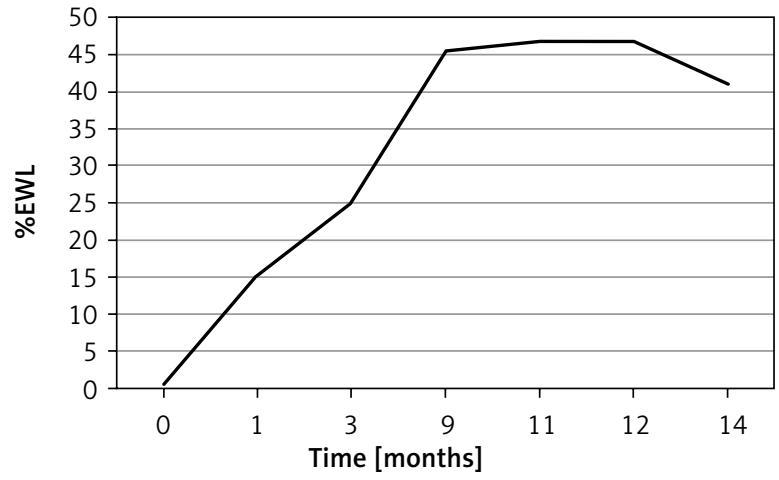

Figure 2. \%EWL

had already been performed (LSG), SADI as the second-stage operation to maximize the weight-losing effect seemed an attractive option.

\section{Single-anastomosis duodenoileal}

On the day of admission the patient weighed $115 \mathrm{~kg}$, corresponding to BMI of $40.75 \mathrm{~kg} / \mathrm{m}^{2}$ (class 3 obesity). She was qualified for a new bariatric operation - SADI. After bringing the patient under general anesthesia, the pneumoperitoneum was formed with a Veress needle inserted under the left costal margin. The laparoscopic procedure was performed using 5 trocars (Figure 3). After freeing the adhesions, the liver was elevated with a laparoscopic retractor, providing an excellent view of the operating field (gastric sleeve and duodenum). The area around the pylorus and the duodenal bulb was exposed and mobilized using a harmonic knife. Dissection of the head of the pancreas and the right gastric artery was performed. Here, approximately $4 \mathrm{~cm}$ distal to the pylorus, the duodenum was cross-cut with a linear stapler (Photo 1). Next, after cutting through the greater omentum, a $200-\mathrm{cm}$ portion of the ileum was measured from the ileocecal valve and anastomosed end-to-side to the proximal end of the duodenum with mechanical suture (linear stapler) (Photo 2) followed by manual suturing of the remaining openings with two layers of PDS 2/0. Using a gastric tube and methylene blue, the final anastomotic leak test was performed, reaffirming water-tightness of the anastomosis. Finally, hemostasis was controlled and low-intensity bleeding from the distal end of the duodenum was stopped with a single metal clip, and a TachoSil Single spiral drain was left in the proximity of the anastomosis. During the whole procedure, restrictive fluid therapy was strictly adhered to. 


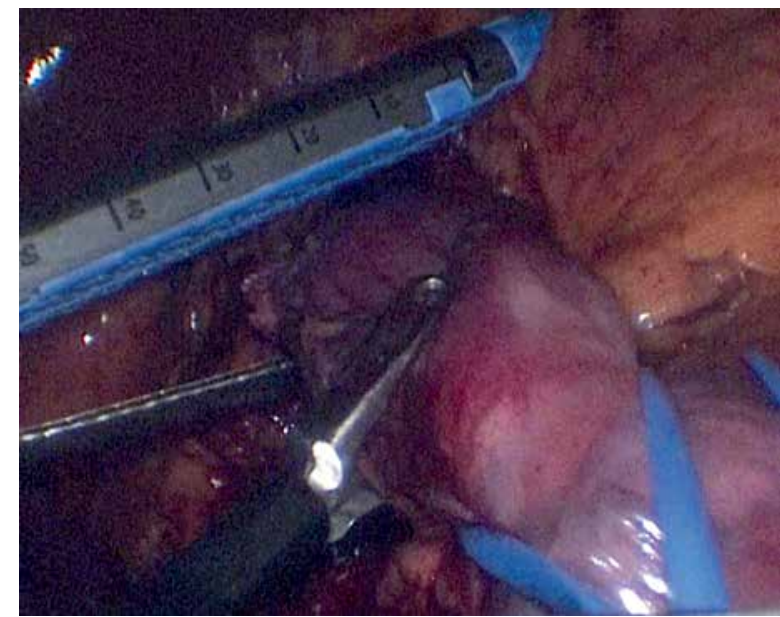

Photo 1. Dividing the duodenum

\section{Postoperative period}

There were no short-term complications. Contrast X-ray of the upper gastrointestinal tract was performed on the first postoperative day (Photo 3), showing no signs of leakage. After drain removal, the patient was allowed to consume small portions of water, which was very well tolerated. She was discharged from the hospital after 5 days of hospitalization. Weight loss of $15 \mathrm{~kg}$ without any complications was observed 30 days after surgery.

\section{Discussion}

Failure of a bariatric procedure must always be considered when planning long-term treatment of extremely obese patients. There is no consensus on what operation should be carried out after failed laparoscopic sleeve gastrectomy [15]. There seem to be three alternative options [4]: conversion to a malabsorptive procedure $[6,7,9]$, "re-sleeve gastrectomy" $[5,8]$ or placement of a laparoscopic adjustable gastric band $[10,16]$. When choosing an appropriate second stage procedure for this group of patients, one must remember that failure of the primary surgery could follow from the fact that laparoscopic sleeve gastrectomy depends mainly on a restrictive mechanism. Obviously, it was not sufficient in this case. Laparoscopic sleeve gastrectomy can be considered a basic operation in the bariatric surgery field. Originally it was used as the first step before Roux-en-Y gastric bypass or duodenal switch. Today it can be a part of more complex procedures such as SADI-S $[13,17]$ or SIPS $[18,19]$, adding its restrictive mechanism to these operations.

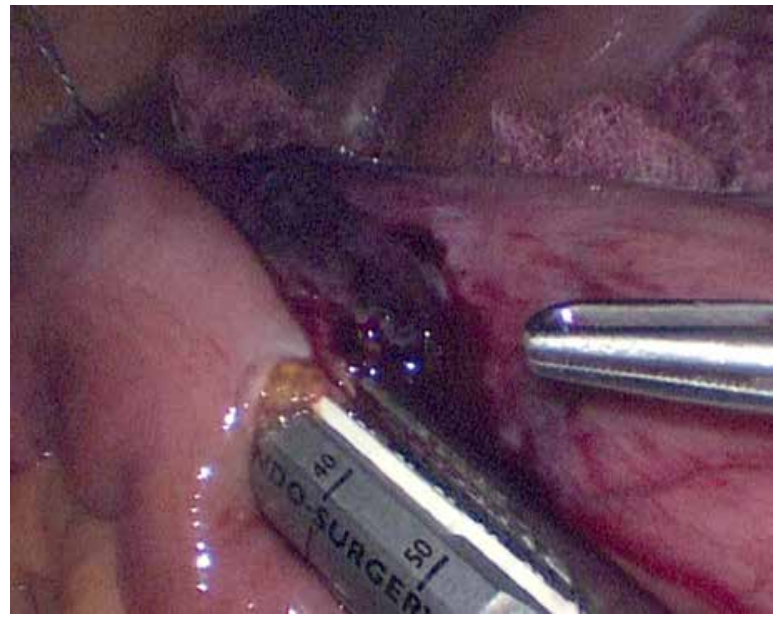

Photo 2. End-to-side anastomosis

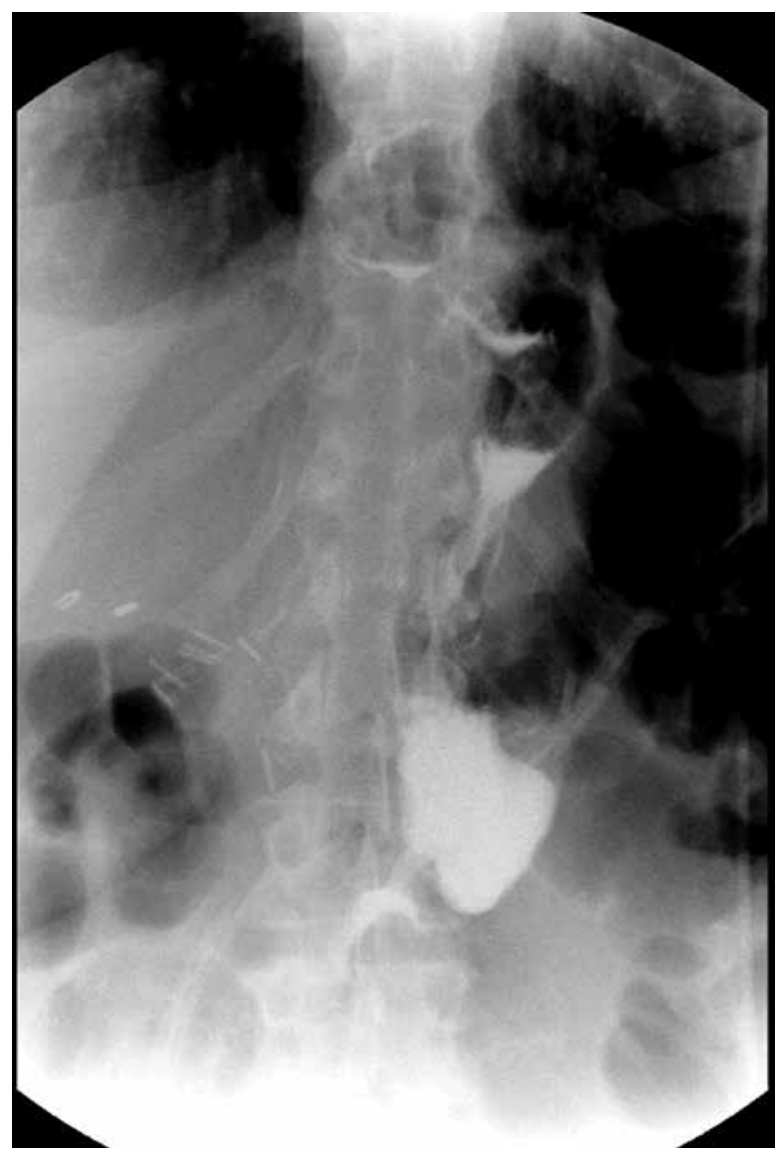

Photo 3. Contrast radiography of upper gastro-

intestinal tract

When considering a revisional, malabsorptive bariatric operation we can choose from a variety of procedures; hence being aware of the differences between them is essential. Biliopancreatic diversion 
Table I. Comparison of possible bariatric revisional procedures

\begin{tabular}{|lccc|}
\hline Parameter & SADI-S & BPD-DS & Mini GB \\
\hline Long-term weight loss & $\begin{array}{c}\text { Short-term outcome } \\
\text { Rewarding }\end{array}$ & Significant & Significant (excellent) \\
\hline $\begin{array}{l}\text { Anastomoses (difficulty } \\
\text { level) }\end{array}$ & 1 & 2 & 1 \\
\hline $\begin{array}{l}\text { Laparoscopic } \\
\text { Bile reflux }\end{array}$ & Yes & Yes & Yes \\
\hline $\begin{array}{l}\text { Potential nutritional } \\
\text { deficiencies }\end{array}$ & Possible & Not anatomically \\
Variable a surgeon \\
$\begin{array}{l}\text { can adjust for the best } \\
\text { outcome }\end{array}$
\end{tabular}

BPD-DS - biliopancreatic diversion - duodenal switch, Mini GB - mini gastric bypass, RYGB - Roux-en-Y gastric bypass.

with duodenal switch is one of the oldest and best known methods. Its significant long-term effects are thoroughly investigated and well proven [20]. On the other hand, it is a difficult procedure, which requires two anastomoses (with greater possibility of leakage). It is proved to cause selective fat malabsorption and nutritional deficiencies if performed in a patient with suboptimal adherence [21]. Roux-en-Y gastric bypass, also requiring two anastomoses, can be performed as well. It can cause nutritional deficiencies and fat malabsorption but also has been shown to cause significant weight loss [22]. Mini-gastric bypass requires only one anastomosis, so it is simpler to perform and has a lower complication rate [23]. It has excellent long-term results, can cause nutritional deficiency [24], but does not result in selective fat malabsorption. The procedure described in this article (SADI-S) is relatively new among bariatric procedures, so its long-term effect is yet to be determined. Short-term outcomes are very promising so far [25] and, when added to its relative simplicity (single anastomosis), make it worth considering among bariatric operations (Table I) [26].

\section{Conclusions}

Single-anastomosis duodenoileal bypass with sleeve gastrectomy is a new, simple and very promising bariatric procedure, which is becoming very popular due to its advantages. It can be performed as one, primary operation, but it also seems to be ideal as a second-stage procedure for patients with laparoscopic sleeve gastrectomy failure. Above all, it has a lower complication rate compared to biliopancreatic diversion with duodenal switch or Roux-en-Y gastric bypass. So far there are not many reports on its long-term effects or complications, so more time for observation is required.

\section{Conflict of interest}

The authors declare no conflict of interest.

\section{References}

1. Weiner RA, Theodoridou S, Weiner S. Failure of laparoscopic sleeve gastrectomy: further procedure? Obes Facts 2011; 4 Suppl 1: 42-6.

2. Rosenthal RJ; International Sleeve Gastrectomy Expert Panel, Diaz AA, Arvidsson D, Baker RS, et al. International Sleeve Gastrectomy Expert Panel Consensus Statement: best practice guidelines based on experience of $>12,000$ cases. Surg Obes Relat Dis 2012; 8: 8-19.

3. Gumbs AA, Pomp A, Gagner M. Revisional bariatric surgery for inadequate weight loss. Obes Surg 2007; 17: 1137-45.

4. Laffin M, Karmali S. An update on bariatric surgery. Curr Obes Rep 2014; 3: 316-20.

5. Noel P, Nedelcu M, Nocca D, et al. Revised sleeve gastrectomy: another option for weight loss failure after sleeve gastrectomy. Surg Endosc 2014; 28: 1096-102.

6. Nevo N, Abu-Abeid S, Lahat G, et al. Converting a sleeve gastrectomy to a gastric bypass for weight loss failure - is it worth it? Obes Surg 2018; 28: 364-8.

7. Carmeli I, Golomb I, Sadot E, et al. Laparoscopic conversion of sleeve gastrectomy to a biliopancreatic diversion with duode- 
nal switch or a Roux-en-Y gastric bypass due to weight loss failure: our algorithm. Surg Obes Relat Dis 2015; 11: 79-85.

8. AlSabah S, Alsharqawi N, Almulla A, et al. Approach to poor weight loss after laparoscopic sleeve gastrectomy: re-sleeve vs. gastric bypass. Obes Surg 2016; 26: 2302-7.

9. Langer FB, Bohdjalian A, Shakeri-Leidenmühler S, et al. Conversion from sleeve gastrectomy to Roux-en-Y gastric bypass: indications and outcome. Obes Surg 2010; 20: 835-40.

10. Greenstein AJ, Jacob BP. Placement of a laparoscopic adjustable gastric band after failed sleeve gastrectomy. Surg Obes Relat Dis 2008; 4: 556-8.

11. Topart P, Becouarn G. The single anastomosis duodenal switch modifications: a review of the current literature on outcomes. Surg Obes Relat Dis 2017; 13: 1306-12.

12. Shoar S, Poliakin L, Rubenstein R, Saber AA. Single anastomosis duodeno-ileal switch (SADIS): a systematic review of efficacy and safety. Obes Surg 2018; 28: 104-13.

13. Sánchez-Pernaute A, Rubio Herrera MA, Pérez-Aguirre E, et al. Proximal duodenal-ileal end-to-side bypass with sleeve gastrectomy: proposed technique. Obes Surg 2007; 17: 1614-8.

14. Bennett JM, Mehta S, Rhodes M. Surgery for morbid obesity. Postgrad Med J 2007; 83: 8-15.

15. Langer FB, Shakeri-Leidenmühler S, Bohdjalian A, et al. Strategies for weight regain after sleeve gastrectomy. Surg Laparosc Endosc Percutan Tech 2010; 20: 159-61.

16. Paluszkiewicz R, Kalinowski P, Wróblewski T, et al. Prospective randomized clinical trial of laparoscopic sleeve gastrectomy versus open Roux-en-Y gastric bypass for the management of patients with morbid obesity. Videosurgery Miniinv 2012; 7: 225-32.

17. Balibrea JM, Vilallonga R, Hidalgo $M$, et al. Mid-term results and responsiveness predictors after two-step single-anastomosis duodeno-ileal bypass with sleeve gastrectomy. Obes Surg 2017; 27: 1302-8.

18. Cottam A, Cottam D, Portenier D, et al. A matched cohort analysis of stomach intestinal pylorus saving (SIPS) surgery versus biliopancreatic diversion with duodenal switch with two-year follow-up. Obes Surg 2017; 27: 454-61.

19. Mitzman B, Cottam D, Goriparthi R, et al. Stomach intestinal pylorus sparing (SIPS) surgery for morbid obesity: retrospective analyses of our preliminary experience. Obes Surg 2016; 26: 2098-104.

20. Topart P, Becouarn G, Delarue J. Weight loss and nutritional outcomes 10 years after biliopancreatic diversion with duodenal switch. Obes Surg 2017; 27: 1645-50.

21. Homan J, Schijns W, Aarts EO, et al. Treatment of vitamin and mineral deficiencies after biliopancreatic diversion with or without duodenal switch: a major challenge. Obes Surg 2018; 28: 234-41.

22. Suter M, Donadini A, Romy S, et al. Laparoscopic Roux-en-Y gastric bypass: significant long-term weight loss, improvement of obesity-related comorbidities and quality of life. Ann Surg 2011; 254: 267-73.

23. Rutledge R, Walsh TR. Continued excellent results with the mini-gastric bypass: six-year study in 2,410 patients. Obes Surg 2005; 15: 1304-8.23.

24. Almalki OM, Lee WJ, Chen JC, et al. Revisional gastric bypass for failed restrictive procedures: comparison of single-anasto- mosis (mini-) and Roux-en-Y gastric bypass. Obes Surg 2018: 28: 970-5.

25. Moon RC, Gaskins L, Teixeira AF, Jawad MA. Safety and effectiveness of single-anastomosis duodenal switch procedure: 2-year result from a single US institution. Obes Surg 2018; 28 : 1571-1577.

26. Janik MR, Stanowski E, Paśnik K. Present status of bariatric surgery in Poland. Videosurgery Miniinv 2016; 11: 22-5.

Received: 2.03.2018, accepted: 15.04.2018. 